\title{
Controle social na saúde complementar em um município brasileiro do noroeste gaúcho: entre a gestão social e a gestão estratégica
}

\author{
Social control in complementary health in a Brazilian municipality of the \\ northwest gaúcho: between social management and strategic management
Control social en salud complementaria en un municipio brasileño del noroeste de gaucho: entre la gestión social y la gestión estratégica

\author{
Juliana da Fonseca Capssa Lima Sausen ${ }^{1}$ \\ Vanilson Viana Cardoso ${ }^{1}$ \\ Daniel Knebel Baggio ${ }^{1}$ \\ Airton Adelar Mueller ${ }^{1}$
}

Recebido em 06/08/2019; revisado e aprovado em 18/12/2019; aceito em 26/02/2020

DOI: http://dx.doi.org/10.20435/inter.v22i2.2671

\begin{abstract}
Resumo: Reflexões têm sido feitas sobre as diferenças e aproximações de conceitos da gestão social e gestão estratégica (CANÇADO; VILLELA; SAUSEN, 2016). No presente artigo, analisam-se as duas abordagens junto aos serviços de saúde complementar, a partir da dinâmica existente entre os arranjos institucionais e a participação dos atores locais no contexto da contratação de serviços do SUS por organizações do terceiro setor. Trata-se de uma política definida pela Constituição Federal que visa promover a sustentabilidade dos territórios em face da distribuição dos recursos para organização da saúde pública hospitalar, especialmente nos pequenos municípios, onde as demandas sociais e as dependências de recursos externos são mais latentes. Desta forma, mediante pesquisa bibliográfica, pesquisa documental e entrevista, buscou-se investigar as práticas de gestão e suas formas de atuação quanto ao controle social da saúde complementar, considerando as inter-relações entre conselho municipal de saúde, instituição hospitalar filantrópica e poder público em um município brasileiro de pequeno porte, localizado no noroeste do Estado do Rio Grande do Sul. Os resultados apontam que a gestão social acontece sob a forma de poucas ações, e o controle social não é efetivo. Enquanto isso, a gestão estratégica prima pela otimização dos recursos disponíveis, permeando as relações políticas e institucionais às quais se submetem o conselho e os demais atores locais envolvidos. Consequentemente, as iniciativas de promover transformações mais efetivas no âmbito da saúde complementar no local de investigação do estudo também são afetadas, uma vez que não se verifica a existência de participação horizontal.
\end{abstract}

Palavras-chave: controle social; saúde complementar; gestão social; gestão estratégica.

Abstract: Reflections have been made on the differences and approximations of concepts of social management and strategic management (CANÇADO; VILLELA; SAUSEN, 2016). In this article, the two approaches to complementary health services are analyzed based on the dynamics existing between institutional arrangements and the participation of local actors in the context of contracting SUS services by third sector organizations. It is a policy defined by the Federal Constitution that aims to promote the sustainability of territories in the face of the distribution of resources for the organization of hospital public health, especially in small municipalities, where social demands and dependencies on external resources are more latent. Thus, through bibliographic research, documentary research, and interview, we sought to investigate the management practices and their ways of acting concerning the social control of complementary health, considering the interrelationships between the municipal health council, philanthropic hospital institution, and public power in a small Brazilian municipality, located in the northwest of the State of Rio Grande do Sul. The results show that social management takes the form of few actions and social control is not effective. Meanwhile, strategic management strives for the optimization of available resources, permeating the political and institutional relations to which the council and the other local actors involved are submitted. Consequently, initiatives to promote more effective transformations in the scope of complementary health at the study's research site are also affected, since there is no horizontal participation.

Keywords: social control; complementary health; social management; strategic management.

\footnotetext{
${ }^{1}$ Universidade Regional do Noroeste do Estado do Rio Grande do Sul (UNIJUÍ), Ijuí, Rio Grande do Sul, Brasil.
} 


\begin{abstract}
Resumen: Se han reflexionado sobre las diferencias y aproximaciones de los conceptos de gestión social y gestión estratégica (CANÇADO; VILLELA; SAUSEN, 2016). En este artículo, se analizan los dos enfoques de los servicios de salud complementarios, en función de la dinámica existente entre los arreglos institucionales y la participación de los actores locales en el contexto de la contratación de servicios del SUS por parte de organizaciones del tercer sector. Es una política definida por la Constitución Federal que tiene como objetivo promover la sostenibilidad de los territorios frente a la distribución de recursos para la organización de la salud pública hospitalaria, especialmente en los municipios pequeños, donde las demandas sociales y la dependencia de los recursos externos están más latentes. Por lo tanto, a través de la investigación bibliográfica, la investigación documental y la entrevista, buscamos investigar las prácticas de gestión y sus formas de actuar en relación con el control social de la salud complementaria, considerando las interrelaciones entre el consejo municipal de salud, la institución hospitalaria filantrópica y el poder público. en un pequeño municipio brasileño, ubicado en el noroeste del estado de Rio Grande do Sul. Los resultados muestran que la gestión social toma la forma de pocas acciones y el control social no es efectivo. Mientras tanto, la gestión estratégica se esfuerza por optimizar los recursos disponibles, permeando las relaciones políticas e institucionales a las que se someten el consejo y los otros actores locales involucrados. En consecuencia, las iniciativas para promover transformaciones más efectivas en el alcance de la salud complementaria en el sitio de investigación del estudio también se ven afectadas, ya que no existe una participación horizontal..
\end{abstract}

Palabras clave: control social; salud complementaria; gestión social; gestión estratégica.

\title{
1 INTRODUÇÃO
}

Consolidado a partir da Constituição Federal (CF) de 1988 (BRASIL, 1988), e em resposta ao debate nacional sobre a universalização, qualificação e acessibilidade dos serviços públicos de saúde, o sistema de saúde pública deu início ao Sistema Único de Saúde (SUS) e ao sistema de saúde complementar, com o intuito de, enquanto dever do Estado e direito de todo o cidadão, promover uma transformação positiva e efetiva nos processos e nas políticas públicas de atendimento à sociedade civil, com vistas a contemplar todo o território nacional.

Considerando este contexto, e as diversas formas de inter-relação e articulação entre os atores institucionais (conselho municipal, prestadores de serviço, profissionais da saúde e usuário), tanto as ações internas quanto as interações externas podem articular-se com práticas de gestão social. Processos participativos são processos educativos em que arranjos institucionais participativos promovem uma pedagogia emancipadora, pois a busca do consenso e do acordo pode promover a autorreflexividade dos agentes envolvidos; e, assim como a participação é conquista, gerenciar territórios por meio da interação dos atores é contribuir para o êxito do bem-estar de uma coletividade territorial (TENÓRIO, 2016a).

Emerge, assim, a relevância do controle social como a capacidade de a sociedade comandar ações na esfera pública (ARAÚJO, 2014), e dos conselhos gestores como espaços de fomento da gestão social (KRONEMBERGER; MEDEIROS; DIAS, 2016), o que torna oportuna a análise das diferenciações e dos conceitos da gestão social e da gestão estratégica.

Com base nisto, Cançado, Villela e Sausen (2016, p. 80) destacam que "o mercadocentrismo vem mostrando suas limitações no mundo atual e abrindo espaço para discussões sobre uma sociedade mais equânime e sustentável". Considerando isso, neste estudo as duas abordagens são analisadas a partir dos arranjos institucionais de organização dos serviços de saúde complementar, incluindo os atores locais da área da saúde e afins.

Os conselhos de saúde tornam-se propostas alcançáveis para práticas de gestão social, desde que exercidas de maneira participativa e igualitária, em prol do bem da comunidade, pelo atendimento de suas demandas, que não são poucas para os serviços desta área, inclusive, para práticas construtivas para o desenvolvimento. Nesta perspectiva, a efetivação do exercício 
do controle pelos cidadãos sobre a ação do Estado exige que o gestor público preste contas de sua atuação (KRONEMBERGER; MEDEIROS; DIAS, 2016). Além do ente público, as instituições filantrópicas recebem subsídios para a execução de atividades de saúde pública mediante acesso universal, igualitário e gratuito direcionado à população.

Contud o o fato de os processos decisórios no Brasil incorporarem com crescente entusiasmo a participação social, se, por um lado, representa inovação que se tornou modelo para outros países, carece, por outro lado, de transformações específicas, seja na cultura administrativa, seja na cultura participativa da sociedade (SILVA; LOPEZ; PIRES, 2010).

Desta forma, é fundamental a identificação e o atendimento das necessidades da sociedade civil, principalmente nos casos da saúde complementar em pequenos municípios, onde as demandas são mais latentes e o acesso aos recursos para viabilização das ações depende, por vezes, da atuação das instâncias mais amplas (SANCHO; GEREMIA; DAIN; GEREMIA; LEÃO, 2017). Torna-se, assim, relevante a investigação das práticas de gestão e perspectivas de controle social no âmbito da saúde complementar diante das atuações e articulações dos atores estatais e sociais em tais localidades, identificando os impactos das instâncias maiores perante esta escala.

Portanto, para fins de contribuir com a transformação e o desenvolvimento deste perfil de instância, e agregar contribuições na área de gestão em políticas públicas, considerando as abordagens sobre gestão social e controle social, este estudo objetiva investigar as formas de atuação e de articulação nos arranjos institucionais de saúde, suas práticas de gestão e a sua relação com as questões de controle social da saúde complementar em um município brasileiro de pequeno porte, localizado na região noroeste do estado do Rio Grande do Sul.

Na sequência, é apresentado o referencial teórico, em que são abordados o contexto e os princípios do sistema de saúde e da saúde complementar no Brasil, as formas de gestão na saúde complementar e o controle social e o papel dos conselhos municipais na saúde enquanto espaços de articulação de atores sociais e estatais. Em seguida, tem-se a metodologia. Após, são apresentados os resultados, destacando as atuações e articulações do Conselho Municipal de Saúde com os demais atores no município investigado, o controle social na contratualização com o SUS em face deste cenário e as formas de gestão evidenciadas neste contexto da saúde complementar. Por fim, tem-se as considerações finais e as referências.

\section{SISTEMA DE SAÚDE E A SAÚDE COMPLEMENTAR NO BRASIL}

Apesar de o sistema de saúde no Brasil ter sido institucionalizado com a criação do Ministério de Saúde, considerando que o período da ditadura militar suplantou tal medida, foi apenas a partir da década de 1980, mediante movimentos ocorridos durante o processo de redemocratização do país, que o sistema de saúde pública efetivamente se consolidou.

Assim, durante as discussões na Assembleia Nacional Constituinte, em 1987 e 1988, o relatório fruto da 8a Conferência Nacional de Saúde (BRASIL, 1986) serviu de base para a concepção social de saúde incorporada à Constituição Federativa do Brasil (BRASIL, 1988). No que tange às atividades voltadas para a saúde, a CF/1988 determina que a saúde é direito de todos e dever do Estado; institui, ainda, os princípios da universalidade, autonomia das pessoas na defesa de sua integridade física e moral, direito à informação às pessoas assistidas sobre a sua saúde e à igualdade da assistência à saúde, sem preconceitos ou privilégios (BRASIL, 1988).

Em resposta ao debate nacional sobre a universalização dos serviços públicos de saúde, um dos destaques da CF/1988 foi a criação do Sistema Único de Saúde. Na sequência, a CF/88 
institui a Lei 8.080/1990 (BRASIL, 1990a) e a Lei 8.142/1990 (BRASIL, 1990b). Enquanto a primeira lei trata da promoção, proteção e recuperação da saúde, a segunda volta-se para a participação comunitária na gestão do SUS e define as transferências de recursos entre os entes, a partir da criação das conferências e dos conselhos de saúde.

A partir deste contexto, a CF/1988 distingue a participação da iniciativa privada entre suplementar e complementar. Enquanto na saúde suplementar ocorre a comercialização de planos de assistência à saúde, a atuação complementar subordina-se às diretrizes do SUS, que, por sua vez, surge a partir dos movimentos sociais que reivindicavam a reforma sanitária no país, pois o sistema criado em 1975 já não operava mais com eficiência, bem como nunca trouxera grandes avanços voltados para a área da saúde (PAIVA; TEIXEIRA, 2014).

E, embora a titularidade de execução possa ser reconhecida e transferida à iniciativa privada, a figura estatal fomenta as políticas públicas propulsoras do SUS, em especial, na formação de uma rede regionalizada e hierarquizada de serviços de saúde, sobretudo no subsídio das ações e dos serviços executados pelas organizações não lucrativas. Assim, na saúde complementar, as atividades são custeadas pelo poder público nas três esferas governamentais (município, estado e União) e executadas a partir das diretrizes do SUS.

Com base nos pressupostos dos sistemas de saúde, o Quadro 1 sistematiza os principais critérios de diferenciação da saúde complementar e da saúde suplementar.

Quadro 1 - Saúde complementar e suplementar: critérios de diferenciação

\begin{tabular}{|c|c|c|}
\hline CRITÉRIO & SAÚDE COMPLEMENTAR & SAÚDE SUPLEMENTAR \\
\hline Origem & Terceiro Setor & Mercado \\
\hline Finalidade & $\begin{array}{c}\text { Não lucrativa, promoção de um } \\
\text { bem coletivo }\end{array}$ & $\begin{array}{c}\text { Lucrativa, exploração de atividade } \\
\text { econômica }\end{array}$ \\
\hline Abrangência & Universal de garantia social & Privada de consumo \\
\hline Financiamento & Recursos públicos & Receitas da carteira de clientes \\
\hline Dimensão de equilíbrio & Controle social & Estado regulador (ANS) \\
\hline Abordagem & $\begin{array}{c}\text { Gestão social (cidadania } \\
\text { deliberativa) }\end{array}$ & Gestão estratégica \\
(competitividade)
\end{tabular}

Fonte: Elaborado pelos autores (2019).

Contudo tal previsão, embora incluída na CF/1988, foi tratada como exceção pela Lei n. 8.080/1990, conforme artigo 24: "Quando as suas disponibilidades forem insuficientes para garantir a cobertura assistencial à população de uma determinada área, o Sistema Único de Saúde poderá recorrer aos serviços ofertados pela iniciativa privada" (BRASIL, 1990a).

A realidade, portanto, mostra-se distinta e, ao mesmo tempo, inversa da referida na previsão constitucional, pois, segundo dados apresentados pelo Ministério da Saúde (MS), apenas no estado do Rio Grande do Sul, do total de 312 organizações hospitalares com perfil de hospital geral $^{2}, 248$ são classificadas como instituições sem fins lucrativos, representando, desta forma, $79,48 \%$ do total da rede hospitalar pertencente ao estado (BRASIL, 2017e).

\footnotetext{
${ }^{2}$ Hospital destinado à prestação de atendimento nas especialidades básicas, por especialistas e/ou outras especialidades médicas. Pode também dispor de serviço de urgência e emergência (BRASIL, 2017f).
} 
Assim, a grande lacuna que surgiu e permanece é com relação ao financiamento das ações do SUS, pois, no início dos anos 1990, muitos estados e municípios já não detinham condições de exercer as competências e atribuições estabelecidas nessas leis, e o governo federal resistia ao financiamento do SUS (PAIM, 2009). Por outro lado, embora haja aumento das ações judiciais reivindicando o direito violado, há quem defenda que os indivíduos estão conhecendo mais seus direitos e a obrigação do Estado em face deles (LEITE; BRITO; SILVA; PALHA; VENTURA, 2014).

Desta forma, a apresentação de tais aspectos demonstra o quão oportuno é este estudo, na medida em que cada vez mais se questiona o papel da gestão e do controle social perante a atuação do terceiro setor junto aos serviços de saúde pública. Tenório (2008) destaca a necessidade de se verificar a efetividade da atuação do setor sem fins econômicos diante das ações de interesse público, sobretudo aquelas financiadas pelo Estado, haja vista o risco de prevalência das práticas tipicamente de mercado nesses contextos. Isso sugere que o objeto legal regulador da saúde pública brasileira - de característica programática e impositiva - padece de maior participação social e do desafio de se procurar compreender os entraves para a concretização dos direitos sociais, na busca por mudanças efetivas na saúde complementar para fins de superar os impasses que separam o SUS da lei do SUS vivenciado no dia a dia.

\section{GESTÃO ESTRATÉGICA E GESTÃO SOCIAL NA SAÚDE COMPLEMENTAR}

A gestão estratégica impera na lógica em que as instituições estão inseridas. O trabalho como evolução, o modelo estratégico de gestão e a burocracia e suas representações são importantes para as instituições e os atores envolvidos e para a ordem, estrutura e organização de uma sistemática nas relações. Embora seja legítima a participação dos técnicos nos processos decisórios, sua inclusão no âmbito das instâncias de participação social pode acarretar a prevalência da gestão estratégica sobre a gestão social, por meio da supremacia de argumentos de cunho técnico, sem a análise e a crítica por parte dos representantes da sociedade civil (ZANI, 2016). E, na área da saúde, esta realidade não costuma ser diferente.

Torna-se, assim, fundamental a reconfiguração dos processos de gestão nas articulações das políticas públicas, sendo indispensável que sejam possibilitados, na gestão pública da área da saúde, espaços mais democráticos que atendam o desenvolvimento das comunidades locais. O desenvolvimento local implica a articulação, em um espaço público, de diferentes atores/ agentes que compõem um determinado território, mediante processos dialógicos, em que os indivíduos têm o direito e o dever de contribuir para o bem-estar de sua comunidade, baseados nos princípios da cidadania, solidariedade e justiça social (TENÓRIO, 2016a).

Tem-se, neste caso, a gestão social como alternativa à gestão estratégica ao tentar sobreporse à gestão tecnoburocrática e monológica, fundamentando-se em uma cidadania deliberativa por meio de um gerenciamento participativo, dialógico, em que as decisões são exercidas por diferentes atores sociais (TENÓRIO, 2016b). Esta gestão considera a autonomia da sociedade perante o Estado e do trabalho perante o capital, baseada na inclusão, no humano enquanto sujeito, no coletivo, na autonomia enquanto liberdade e emancipação, na informalidade e flexibilidade, na linguagem como evolução, no conhecimento reflexivo e construído, na comunicação pela interação e argumentação, na cooperação e na solidariedade.

Por um lado, a realidade que se tem observado na saúde complementar é a de uma prática mais coerente com a gestão estratégica, principalmente no contexto dos municípios 
menores - que dependem de recursos de instâncias maiores para acesso da população aos serviços prestados. Portanto não significa que devamos desprezar as tecnologias gerenciais, mas reconstruir, criticamente, a racionalidade de mercado de origem instrumental, apolítica, em prol de uma racionalidade que promova a intersubjetividade deliberativa das pessoas alicerçadas no potencial do sujeito social e também na cidadania (TENÓRIO, 2016b).

Faz-se, portanto, cada vez mais necessária a incorporação de práticas de gestão social nos processos internos e externos, com vistas a contemplar a saúde complementar dos pequenos municípios, incluindo a participação dos conselhos gestores, das instituições prestadoras de serviço e a inter-relação dos agentes e dos atores institucionais.

\section{CONTROLE SOCIAL E O PAPEL DOS CONSELHOS MUNICIPAIS NA SAÚDE}

Principal canal de participação cidadã nas três instâncias do governo e de espaços públicos potenciais para a prática da gestão social (KRONEMBERGER; MEDEIROS; DIAS, 2016) e do controle social como a capacidade de a sociedade controlar ações na esfera pública (RICCl, 2009), os conselhos gestores procuram articular diferentes atores da sociedade civil que, em interação com o Estado e com o capital, vocalizam pretensões para planejar, executar e avaliar políticas públicas ou decisões em prol do bem comum (TENÓRIO, 2016c).

O setor de saúde exerceu importante e pioneiro papel na institucionalização dos conselhos municipais no Brasil, pois, com a Reforma Sanitária - ocorrida na década de 1980 e que reivindicava um Estado mais ativista, em paralelo com as reivindicações populares de controle público por parte dos movimentos populares -, foram lançadas as bases para que a Constituição Federal (CF) de 1988 incorporasse as diretrizes para a participação social na gestão das políticas públicas, por meio da criação dos conselhos gestores, formalizados enquanto instâncias colegiadas do SUS, pela Lei Federal n. 8.142/1990 (BRASIL, 2017d).

Assim, pode-se inferir que não há nada que se assemelhe aos conselhos de saúde, devido a sua representatividade social, pela gama de atribuições e poderes legais investidos e pela extensão em que estão implantados no país, nas três esferas governamentais (ARAÚJO, 2014). Além disso, um dos seus elementos mais importantes é a associação entre a falta da participação e sanção, expressa na suspensão da transferência de recursos públicos federais para os municípios que não praticarem a participação popular na saúde (AVRITZER, 2008).

Os conselhos de saúde estão instituídos em todos os municípios brasileiros, sendo que a sua existência é pré-requisito para o repasse de verbas e de outros incentivos aos municípios. Entre as competências dos conselhos de saúde, estão a definição das diretrizes para a elaboração dos planos de saúde, os programas de saúde locais, a elaboração dos convênios, a aprovação das propostas orçamentárias e, por fim, a fiscalização e o acompanhamento do desenvolvimento das ações e dos serviços de saúde (ARAúJO, 2014).

Na saúde pública, os conselhos representam a melhor alternativa para a participação da sociedade civil na definição das políticas públicas de saúde. Neste cenário, é um grande desafio fazer com que os órgãos de controle social ampliem o debate com a comunidade e os gestores para o fortalecimento dos princípios da integralidade, universalidade, descentralização e participação social do Sistema Único de Saúde (AVRITZER, 2008).

A melhor participação cidadã é a que se mantém alerta e presente no atendimento a demandas não atendidas com a devida importância (ARAÚJO, 2014). Desta forma, torna-se real a possibilidade de canalização e de identificação de necessidades, além da cobrança de melhor 
desempenho dos serviços públicos de saúde nos conselhos, principalmente em casos da saúde complementar e em pequenos municípios, onde as demandas são mais latentes.

A princípio, gestores, prestadores de serviços, trabalhadores e usuários devem ter assegurada sua participação no processo decisório, sendo de responsabilidade de todos o controle sobre as ações, bem como sobre os serviços de saúde (ARAÚJO, 2014). Porém, considerando que nos conselhos de saúde existem diferentes escalas de poder e de interesses, é instigante refletir sobre como essas relações podem ser trabalhadas e de que forma esses canais de participação podem ser efetivos para o controle social das políticas públicas.

Afinal, apesar dos conselhos serem instituições constituídas mediante um processo de partilha do poder na qual atores estatais e da sociedade civil participam ativamente e simultaneamente (AVRITZER, 2008), e embora nas relações entre Estado e sociedade tenha ocorrido um deslocamento da matriz estadocêntrica para a matriz sociocêntrica (PAULA; KEINERT, 2016), além das diferenças entre os próprios conselhos, observa-se que o processo de democratização na saúde acompanha o processo distante de democratização da sociedade.

Em outras palavras, o exercício da participação e do controle social é dificultado pela assimetria de saber e de poder dos conselheiros e, em um contexto mais amplo, pelas assimetrias entre a representação da sociedade civil e a representação estatal (PAULA; KEINERT, 2016). São evidenciados, ainda, a apatia e o desconhecimento da sociedade civil quanto às propostas e ações dos conselhos. Sociedade esta que deveria ser a principal interessada e engajada nas questões de caráter público com a finalidade de transformação e desenvolvimento das instâncias locais, regionais e em nível macro, especialmente em se tratando de questões complexas e importantes que envolvem a saúde pública e seu entorno.

Decidir sobre os caminhos da saúde pública dos municípios é, portanto, um grande desafio. A constituição dos conselhos municipais parte do pressuposto de que eles deveriam ser espaços de participação social na administração pública, possibilitando um novo modo de pensar e de fazer saúde, com espaços para práticas de renovação e de transformação na saúde.

\section{PROCEDIMENTOS METODOLÓGICOS}

Esta pesquisa classifica-se como social e de abordagem qualitativa. Social, pois envolve aspectos relativos ao ser em seus múltiplos relacionamentos com outros seres e instituições sociais; qualitativa, pois buscou aprofundar-se no mundo dos significados (GIL, 2019). Referente aos objetivos, a pesquisa classifica-se como exploratória e descritiva.

Exploratória, pois é realizada em área com pouco conhecimento acumulado e sistematizado (GIL, 2019). Assim, buscou agregar resultados, destacando contribuições com a conceituação da gestão social e gestão estratégica na saúde complementar, com foco em pequenos municípios, onde há mais demandas sociais. Descritiva, pois descreve características de um fenômeno, estabelecendo relações entre variáveis e a natureza destas relações (GIL, 2019), mediante formas de atuação e articulação nos arranjos institucionais de saúde, suas práticas de gestão e a sua relação com o controle social na saúde complementar.

Além disso, para maiores constatações e subsídios acerca da relevância e da aplicabilidade da temática proposta, realizou-se um estudo de caso (YIN, 2001), em um município brasileiro de pequeno porte, localizado na região noroeste do Rio Grande do Sul.

Para alcançar os objetivos do estudo, foram utilizadas pesquisa bibliográfica, pesquisa documental e entrevista. A pesquisa bibliográfica, realizada em livros e trabalhos científicos, 
permitiu a construção do referencial teórico. A pesquisa documental incluiu análise da Constituição Federal, além de leis e portarias nacionais, especialmente sobre saúde e saúde complementar. Para maior conhecimento das práticas de articulação e de gestão nos arranjos institucionais de saúde complementar, realizou-se entrevista semiestruturada com o presidente do Conselho Municipal de Saúde, também administrador do hospital do município em estudo.

\section{SAÚDE COMPLEMENTAR: CONTROLE SOCIAL E PRÁTICAS DE GESTÃO}

\subsection{Conselho Municipal de Saúde: atuações e articulações}

O Conselho Municipal de Saúde (CMS) da localidade estudada foi constituído em 1987, após a emancipação do referido município - de população de quatro mil habitantes e que vive da agricultura e pecuária familiares -, tendo iniciado suas atividades com a instalação da sede do município um ano após. Este conselho é constituído por 16 membros em paridade de gestores, prestadores de serviços, profissionais de saúde e usuários. Conforme o presidente do CMS e administrador do hospital do município: "Naquela época já tínhamos as entidades que faziam parte. Não sei se já tinha a paridade, mas era indicado, já era pensado".

Entidades participantes costumam ser as mesmas. "Quase sempre o mesmo grupo participa". O ingresso de membros ocorre por portaria via gestão pública. "Praticamente a cada dois anos deve haver uma nova divulgação. O município consolida a portaria de membros titulares e suplentes, cabendo ao gestor determinar as trocas dos membros via nova portaria, caso a entidade queira". Há voluntários e indicações de pessoas de fora e de dentro do conselho, caso alguém não se disponibilize. "É um processo misto, tanto de voluntariado como também por indicação". A convocação de reuniões, realizadas mensalmente, é feita pelo presidente, e a divulgação é feita pela Secretaria Municipal de Saúde (SMS).

Ações implementadas restringem-se à análise e aprovação de projetos e trâmites burocráticos. "Nosso conselho é consultivo. O conselho tem mais o propósito de aprovar projetos e prestação de contas. O que normalmente está acontecendo é apagar incêndio. Na verdade, ele deveria ser mais para pensar e planejar um pouco da política de saúde".

Com base nestas considerações, as últimas discussões pautadas no conselho de saúde do município em análise foram: aprovação de prestação de contas pelo setor de saúde do município, logística para doação de sangue e discussão sobre os impactos e perspectivas da PEC 241 - que propõe alteração do regime fiscal dos órgãos federais pelos próximos 20 exercícios fiscais, a ser corrigido pela variação do Índice de Preços ao Consumidor (IPCA).

As ações do Conselho Municipal de Saúde refletem nas suas relações estabelecidas com as instituições do poder público. "Convocamos a Conferência Municipal de Saúde, participamos da Conferência Estadual de Saúde e as ações em conjunto também foram boas. O conselho não aprofunda muitas coisas. Muitas vezes não analisa os documentos, e sim olha os números apresentados e questiona algumas dúvidas. Assim, não acaba criando atrito".

Apesar da parceria com entidades locais (instituições sociais e de terceira idade, hospitais, escolas, sindicatos educacionais e cooperativas), os recursos das ações analisadas pelo conselho originam-se dos governos federal, estadual e municipal e, em alguns casos, de emendas parlamentares e consulta popular, mas todos seguem o rito dos recursos públicos. O Conselho Municipal de Saúde depende do poder público quanto aos recursos, espaço físico, equipamentos, diligências, arquivamento de documentos, entre outras decisões e ações. 
Deliberações acontecem, muitas vezes, por interesses políticos dos membros, e muitos assuntos ficam sem solução, para evitar atritos. "Em pequenos municípios, a questão política está bem definida, então muitas vezes fica aquela questão: está insistindo porque é da posição, não quer passar informação porque é da situação. Muitas vezes, não se questiona".

Além disso, várias questões não são consideradas atribuições do Conselho Municipal de Saúde pela gestão pública. "Fora as reuniões periódicas e a apresentação do plano operativo para o Estado junto ao gestor municipal, não têm acontecido debates. A discussão do contrato do hospital com o município, muitas vezes, não é levada para o conselho".

Reuniões acontecem por demandas do hospital, laboratórios, Secretarias Municipais de Saúde e município. Nem todos os conselheiros participam. "Normalmente não participam mais que nove, dez pessoas, de dez a doze pessoas no máximo". Falta espaço e profissional apropriados para debate, e os encontros acontecem em sala de reuniões do poder público.

Decisões e ações são conjuntas, por votação, em espaço aberto, transparente, solidário e respeitoso. "A autoridade da decisão se dá com todo o conselho. Quem é contra se manifesta, senão consideramos aprovado". O espaço, porém, é restrito aos conselheiros e à administração pública. Diferentemente do que um dia já foi, pois já houve interesse maior de participação comunitária, o espaço quase não é utilizado nem divulgado. "Teve momentos em que pessoas da comunidade participaram nas reuniões, mas não há interesse em divulgar".

Além do mais, não existe preparação dos conselheiros para entenderem ou interagirem com questões de controle social. "A dificuldade é achar pessoas disponíveis para compor os conselhos e que tenham domínio na área da saúde. Muitos conselheiros participam, mas muitas vezes não questionam, não chegam ao ponto de formar uma questão".

Parcerias são divulgadas pelo conselho por meio de programa de rádio, mas a gestão pública limita-se a repassar maiores informações. "Nos programas semanais, levamos o máximo de informações, tentamos ser o mais transparente possível. Mas o programa da prefeitura, quanto ao informativo da saúde, se restringe à agenda e roteiros de atendimento".

Porém hospital e conselho costumam dialogar entre si. "Quando vou em uma reunião do consel ho e tem assunto do hospital, abro espaço para questionamentos. Mesmo o hospital sendo privado, a atuação é praticamente pública, pois noventa por cento do faturamento vem do SUS. o que querem saber e o que sabemos que é e deve ser importante, temos colocado".

Diante deste cenário, cabe destacar que o presidente do conselho municipal não é representante da sociedade civil. "A função do presidente não poderia ser exercida pelos prestadores de serviço e pelo gestor, deveria ser exercida pelo usuário ou trabalhador de saúde, mas não tivemos ninguém que se achou em condições de assumir a presidência".

O presidente do conselho reconhece as limitações. Apesar da atuação e do envolvimento com as questões da saúde pública municipal, afirma que o conselho evoluiu pouco desde sua implementação e elenca a criação de um espaço específico mais amplo para debater, qualificar conselheiros e divulgar informações de acesso popular. Considera, porém, que não há interesse do cidadão nos debates, que muitos problemas de saúde se devem por descuido de pacientes e familiares, e que a sociedade cobra sem considerar a gratuidade na saúde.

Além disso, o cidadão do município estende a falta de comprometimento da gestão pública para as instituições, prejudicando a adesão aos serviços. "Mesmo o hospital prestando um serviço pactuado com o gestor público, o pessoal acha que tem que fazer mais. Não estão interessados em saber se o hospital recebe ou não, querem garantir o direito deles". 
Tais aspectos são reflexo do posicionamento centralizador do poder público diante dos atores institucionais da saúde complementar do município. "O gestor municipal não colocou em apreciação do conselho a questão do turno único da saúde". Por questões de comodidade e praticidade, a gestão municipal também não comunica a sociedade sobre a importância de priorização da atenção básica para casos de urgência e emergência. "O cidadão quer ir primeiro no hospital buscar o serviço que poderia ser buscado na atenção básica, e o hospital, muitas vezes, não consegue atender as várias demandas de atendimento e horário".

Por fim, verifica-se que há percepção por parte da gestão deste Conselho Municipal de Saúde quanto aos conflitos e às limitações evidenciados nas relações internas e externas e na sua infraestrutura. Do mesmo modo quanto à importância de um conselho deliberativo para atendimento das demandas comunitárias de saúde e à falta de práticas de uma efetiva cidadania deliberativa, uma vez que o cidadão local não tem participação ativa nas decisões, considerando a afirmação de que a divulgação das ações e dos debates nem chega a ele.

\subsection{Controle social na contratualização com o SUS}

Partindo do pressuposto de que controle social não é sinônimo de consulta, feedback, escuta de demandas ou persuasão sobre reinvindicações; sobrevém, de outro lado, uma relação de cogestão. Assim, compreende-se que se está diante de um processo de planejamento e execução definido e monitorado por um conjunto de atores (RICCl, 2009), e esta articulação pode ocorrer em nível local, nacional ou mediante relações internacionais.

Neste caso, buscou-se analisar como se dá o controle social, a partir das relações entre o hospital, o conselho municipal de saúde da localidade estudada e o poder público. Pois a referida organização hospitalar detém personalidade jurídica de associação privada sem fins lucrativos, certificada como Entidade Beneficente de Assistência Social (CEBAS) na área da saúde, conforme Portaria MS n. 1.106/2014 (BRASIL, 2014). Por não visar lucro, a instituição hospitalar mencionada pode apropriar-se de algumas prerrogativas, como a imunidade tributária, conforme previsão constitucional. O principal diferencial, no entanto, refere-se à possibilidade de esta instituição firmar contratos administrativos ou convênios entre o hospital filantrópico e os gestores do Sistema Único de Saúde nos três níveis da Federação.

De acordo com o presidente do CMS do município estudado, para que se proceda com o firmamento de convênio entre a instituição hospitalar enquanto prestadora de serviços e a Secretaria Estadual de Saúde (SES), exige-se que o conselho aprove o Plano Operativo ${ }^{3}$, valendo o mesmo para as contratações firmadas com o município, por meio da SMS.

Analisando as disposições da Portaria MS n. 1.034/2010, verifica-se que se trata de um requisito legal. Ademais, a Lei Federal n. 8.142/1990 (BRASIL, 2017d) estabelece que a conferência e o conselho de saúde formam as instâncias colegiadas do SUS. Destaca-se, ainda, que esta norma faz referência à participação da comunidade na gestão do SUS e às transferências intergovernamentais de recursos financeiros na saúde (BRASIL, 2017d).

Por fim, a compreensão e implementação do controle social junto ao SUS, em especial a formulação de propostas e contratualizações entre terceiro setor e poder público, apresentam incongruências em face da proposta de uma gestão compartilhada (cogestão). Tais dissociações

${ }^{3}$ Documento por intermédio do qual a instituição hospitalar oferta a prestação de serviços de saúde ao gestor do SUS, em caráter complementar, integrando ajustes entre o ente público e a instituição privada (BRASIL, 2010). 
entre previsão legal e prática se originam nas interpretações equivocadas sobre o termo controle social, assim como do instituto. Não raras vezes, confunde-se tal prerrogativa coletiva com mera aprovação ou rejeição de uma proposta, a exemplo do Plano Operativo apresentado por instituições do terceiro setor ao gestor público, como neste caso em estudo.

O controle social na saúde complementar não se opera mediante a fiscalização do convênio firmado entre a administração pública e a instituição hospitalar, apesar do acompanhamento da execução também ser uma prerrogativa dos atores envolvidos, a exemplo da atuação esperada do próprio CMS e, em caráter externo, do Ministério Público (MP), Tribunal de Contas do Estado (TCE), entre outros. O mesmo infere-se sobre as atividades de Vigilância Sanitária (VISA), que também não podem ser confundidas com controle social, uma vez que decorrem do poder de polícia do Estado, que se estende para toda a sociedade.

Desta forma, uma definição segura para o controle social decorre da efetiva "[...] participação da sociedade civil na elaboração, acompanhamento e verificação (ou monitoramento) das ações de gestão pública" (RICCI, 2009, p. 9). Significa definir diretrizes, realizar diagnósticos, indicar prioridades, definir programas e ações, bem como avaliar os objetivos, na medida em que os processos são desenvolvidos, para posterior implementação.

Analisando o contrato entre o hospital da localidade analisada e a SES/RS para o período de 2016/2017, verifica-se que são estabelecidas metas qualitativas e quantitativas, sendo que o não cumprimento dessa pactuação pode acarretar penalização, mediante corte dos valores cujos repasses foram previamente definidos no convênio, podendo resultar na suspensão total ou na rescisão unilateral da contratualização. Contudo esse acompanhamento pelo poder público não substitui a atuação comunitária na gestão perante a saúde pública.

Ocorre que o convênio firmado entre o ente público e a instituição privada pressupõe a existência de interesse comum, que justifique o firmamento de uma parceria cujo objetivo é a prestação de serviços assistenciais à saúde, os quais assegurem acesso universal e igualitário aos cidadãos. Sendo assim, em ambos os casos, a análise primordial que envolve a atuação complementar de instituições não lucrativas no SUS deve questionar a validade da representação exercida por tais organizações, uma vez que expressam insuficiência de cobertura assistencial do poder público à população de uma determinada área ou região.

Segundo o presidente do CMS e administrador do hospital da localidade estudada, a atuação do conselho em face da contratualização do hospital local com o SUS restringe-se a aprovar o Plano Operativo e, em algumas ocasiões, deixa de apreciar os convênios firmados com a Secretaria Municipal de Saúde por ausência de encaminhamento do município.

As duplas funções do entrevistado (presidente do CMS e administrador do hospital) representam uma limitação à perspectiva da esfera pública, sobretudo do bem comum. Ocorre que a interface com o gestor municipal e estadual do SUS se dá mediante a lógica instrumental, de tal modo que os interesses locais acabam chocando-se com os da própria instituição hospitalar, e isso rechaça o viés equânime e sustentável objetivado pela Constituição Federal, ao definir o processo de complementação dos serviços de saúde pública.

Basta ver que a oferta de serviços não tem a discussão fomentada na comunidade local, embora a comunidade seja a principal interessada e beneficiada com os recursos aportados. Consequentemente, as tomadas de decisão limitam-se à atuação gerencial da organização do terceiro setor, estando à mercê do espectro do mercado (TENÓRIO, 2008). 
Por fim, apesar de se verificar a pouca atuação do Conselho Municipal de Saúde como espaço privilegiado para o exercício do controle social, não se trata do único espaço para a gestão participativa da comunidade junto ao Sistema único de Saúde. Ocorre que, dada a natureza jurídica da instituição hospitalar, permite-se, de acordo com a carta estatutária, que a coletividade local se associe e obtenha a prerrogativa de integrar a assembleia geral, instância máxima da organização, na qual se pressupõe que sejam discutidos os principais objetivos para o atendimento das reais demandas e necessidades acerca da comunidade em questão.

\subsection{Saúde complementar: gestão social ou gestão estratégica?}

Partindo-se da análise sobre gestão social e gestão estratégica, os resultados da entrevista e da análise documental apontam que a efetividade do controle social é diretamente influenciada pela abordagem preponderante na atuação da organização. Ou seja, considerando que a submissão do Plano Operativo à apreciação do CMS subentende uma "extensão burocrática e executiva" (ASSIS; VILLA, 2003, p. 377), os objetivos da instituição não se alinham com a concepção de que os cidadãos estejam no centro da formulação de propostas alusivas à prestação de serviços na área da saúde, regulados pelas diretrizes do SUS.

A gestão social, como visto, origina-se como contraponto à gestão estratégica e sugere a preponderância da cidadania deliberativa (TENÓRIO, 2016b). Na saúde complementar, trata-se de um conjunto teórico que se baseia na dialogicidade e no compartilhamento do poder nos processos decisórios que envolvem os diferentes atores atuantes neste contexto.

No caso em estudo, buscou-se investigar como se opera o controle social em um conselho municipal de saúde e em um hospital filantrópico, integrante da rede de serviços do SUS. Para a realização desta análise, é necessário que se defina qual abordagem melhor se aplica às organizações do terceiro setor: deliberativa (gestão social) ou instrumental (gestão estratégica), pois, independentemente do resultado prevalecente, de acordo com o ordenamento jurídico pátrio, incluindo-se as garantias fundamentais e o rol de diretrizes do Sistema Único de Saúde, o controle social se sobressai como condicionante da efetiva gestão democrática da saúde pública, ao mesmo tempo em que é um dever a ser posto pela norma.

Não raras vezes, podem surgir divergências de interesses entre os atores incumbidos de alavancar o controle social sobre determinada proposta, prejudicando o compartilhamento da gestão das atividades de saúde desempenhadas. Apesar de o presidente do CMS e administrador do hospital não referenciar a competitividade, este cita que a gestão estadual do SUS promove ajustes estruturais na rede hospitalar para centralizar alguns serviços nos grandes centros. Tratando-se de política de governo, o controle social pode ficar em segundo plano e resultar na mobilização local e regional em face do que a coletividade interessada pode julgar prejudicial. Não obstante, a notoriedade diante do poder público de um Plano Operativo formulado por outra instituição pode gerar disputa com outro hospital interessado.

Assim, não se pode negligenciar que a disputa oriunda da divergência de interesses possa resultar em um ambiente competitivo, semelhante às atividades de mercado. Logo, a implementação de estratégias voltadas para a competição, em vez de consenso e harmonização dos interesses coletivos, pode não ser a propriedade mais adequada para se analisar as atividades das instituições comunitárias, com vistas às demandas coletivas.

Há diferentes formas de exercer o controle social junto às atividades de uma instituição hospitalar integrante do SUS. Neste caso, parte-se da prerrogativa legal atribuída ao CMS, pois, 
de acordo com o MS (BRASIL, 2013), o papel do colegiado abrange desde a formulação de ações no âmbito das políticas de saúde, até o controle da execução em sede dos resultados alcançados e dos recursos econômicos e financeiros empregados.

Contudo, conforme informações da entrevista realizada com o presidente do CMS e administrador do hospital do município estudado, grande parte da atuação do colegiado se restringe a aprovar, sem muitos questionamentos, as contas de projetos executados pelo hospital, assim como a proposta do Plano Operativo de contratualização com o poder público.

E, apesar do interesse coletivo na atuação do hospital, as atividades executadas são quase que, na totalidade, financiadas com recursos públicos dos três níveis federativos. Segundo Demonstração do Resultado de Exercício 2016 (DRE) e Balanço Patrimonial publicado pelo hospital, 74\% do total de receitas apuradas decorrem de contratos firmados via SUS, como atendimentos ambulatoriais, internações, pronto atendimento 24 horas, leitos de saúde mental, entre outras atividades reguladas por normas de direito público.

Diante disso, a natureza associativa da instituição hospitalar conveniada com o SUS não pode ser confundida com corporativismo, dado que os princípios do Sistema Único de Saúde preconizam acesso universal e igualitário para qualquer pessoa, sem distinção alguma.

\section{CONSIDERAÇÕES FINAIS}

Tendo como base a relevância da temática fundamentada neste estudo e os resultados obtidos mediante pesquisa documental e entrevista, este estudo cumpriu com o objetivo de investigar as formas de atuação e de articulação dos arranjos institucionais de saúde, suas práticas de gestão e sua relação com o controle social na saúde complementar em um município brasileiro de pequeno porte, localizado na região noroeste do Rio Grande do Sul.

Verificou-se, por meio dos dados obtidos, que no plano jurídico-legal há a expressa previsão de que o Plano Operativo formulado durante as negociações entre hospital e poder público deve ser objeto de intervenção, análise, apreciação e deliberação do Conselho Municipal de Saúde, sob pena de a proposta não ser recepcionada pela administração pública.

Apesar de não haver dúvidas acerca do papel desempenhado pelos conselhos de saúde enquanto espaços privilegiados para a articulação de atores sociais e estatais, em especial, na defesa da universalização do acesso aos serviços de saúde, o controle social sobre a atuação das instituições conveniadas com o SUS é tema que merece um melhor aprofundamento.

Neste caso, tem-se uma relação triangular envolvendo a sociedade, o poder público e a organização hospitalar, refletindo em uma exceção ao dever constitucionalmente atribuído ao Estado brasileiro de prestar, direta ou indiretamente, os serviços de saúde. Assim, pode a administração pública recorrer à oferta da iniciativa privada quando suas disponibilidades não forem suficientes para assegurar a assistência devida à população de uma determinada região.

Contudo percebem-se falhas nas inter-relações dos atores envolvidos na saúde complementar do município analisado, incluindo o Conselho Municipal de Saúde, o hospital filantrópico, a administração pública municipal - que coordena a dinâmica de processos dos serviços de saúde para a comunidade -, o poder público em instância maior e, ainda, a própria sociedade civil, que carece também de maior percepção e de maior capacitação quanto às questões de controle social no âmbito da saúde complementar nesta localidade.

A atuação do CMS do município analisado é bastante tímida, tem dificuldades em promover discussões sobre os assuntos pautados, limitando-se, na maioria das vezes, a votar e lavrar em 
ata pareceres favoráveis às propostas de contratualização do hospital local com o gestor estadual do SUS. Soma-se a isto a fragilidade no controle social referente às atividades da organização hospitalar, em que a articulação entre esta instituição e o poder público local restringe-se à mera contratação de serviços prestados, dispensando-se a atuação do CMS na avaliação e, também, na discussão sobre eventuais planos de ações e de metas.

Assim, a gestão social acontece sob a forma de poucas ações, e o controle social não é efetivo. Paralelamente a isto, além de primar pela otimização dos recursos disponíveis, as práticas de gestão estratégica permeiam as relações políticas e institucionais às quais se submetem o conselho e os demais atores locais envolvidos. Inevitavelmente, isso macula as práticas de gestão social, desestimulando relações mais transparentes, conciliadoras e igualitárias entre os atores, em prol de atender, o máximo possível, às demandas de bem-estar e de saúde dos cidadãos. Ademais, os aspectos fundantes do controle social se originam, neste caso, da relação entre sociedade, Estado e terceiro setor, em prol de práticas sustentáveis de desenvolvimento no contexto da saúde complementar, em nível local e regional, bem como em contextos maiores.

Diante do papel atribuído às organizações do terceiro setor, verificou-se que a gestão social detém propriedades que privilegiam a cidadania deliberativa, devendo preponderar sob a gestão estratégica, uma vez que a necessidade de otimização dos recursos prejudica o objetivo maior da política complementar de saúde, que é a ampliação da oferta de serviços do SUS. Assim, as ações alicerçadas pelas instituições filantrópicas, na dimensão estratégica, podem acabar restringindo o interesse coletivo, em benefício do interesse corporativo.

Pelo contrário, deve-se almejar resultados sociais, cujo meio pode ser, entre outras formas, a ampliação dos serviços de saúde ofertados à população, em articulação com outros setores (educação e assistência social, especialmente). Do mesmo modo, é importante fomentar a participação da comunidade na gestão do SUS, mediante realização de conferências, audiências públicas, ampliação do quadro de associados e, principalmente, abertura e estímulo para que o CMS exerça efetivamente o seu papel em face do controle social.

Evidencia-se, por conseguinte, a relevância deste estudo quanto às práticas de gestão e às perspectivas de controle social no âmbito da saúde complementar, diante das atuações dos agentes envolvidos no contexto de análise. Desta forma, a partir da realidade estudada, são fortes as evidências de que municípios de pequeno porte - apesar de constatadas as relações sociais e políticas entre os atores envolvidos - são propensos a lacunas quanto ao fortalecimento das articulações estabelecidas e, também, a demandas por ações sustentáveis, para fins de promover um efetivo atendimento das necessidades latentes da sociedade civil.

Constata-se, ainda, as contribuições teóricas e empíricas do estudo para abordagens sobre sistemas de saúde, saúde complementar e gestão social, em prol desta gestão e do controle social. Evidencia-se, por conseguinte, a relevância da pesquisa para acadêmicos, docentes e teóricos das áreas da gestão, políticas públicas, saúde e desenvolvimento, e para gestores e profissionais estatais, sociais e administrativos das instituições estudadas e demais instituições similares, possibilitando o desenvolvimento nestes locais e em suas comunidades.

Por fim, com o objetivo de complementar a pesquisa, sugerem-se estudos de caso ou multicaso acerca das atuações da gestão e do controle social na saúde complementar, em outros municípios de pequeno porte. E, para fins comparativos, buscando contribuir com novas perspectivas, indicam-se estudos sobre a temática em municípios de médio e grande porte, considerando, ainda, as percepções dos diversos atores envolvidos neste contexto. 


\section{REFERÊNCIAS}

ARAÚJO, C. A. Construindo a gestão social em conselhos municipais de saúde: espaço para o exercício do saber e participação. 2014. 127 f. Dissertação (Mestrado em Gestão Social, Educação e Desenvolvimento Local) - Centro Universitário Una, Belo Horizonte, MG, 2014.

ASSIS, M, M. A.; VILLA, T. C. S. O controle social e a democratização da informação: um processo em construção. Revista Latino-Americana de Enfermagem, Ribeirão Preto, v. 3, n. 11, p. 376-82, 2003.

AVRITZER, L. Instituições participativas e desenho institucional: algumas considerações sobre a variação da participação no Brasil democrático. Opinião Pública, Campinas, v. 14, n. 1, p. 43-64, jun. 2008.

BRASIL. Portaria n. 1.106, de 21 de outubro de 2014. Defere o pedido de Renovação do Certificado de Entidade Beneficente de Assistência Social, na área de Saúde, à Associação Hospitalar Santa Rita, com sede em Jaboticaba (RS). Diário Oficial da União, Brasília-DF, 21 out. 2014, p. 38.

BRASIL. Ministério da Saúde. Conselhos de saúde: a responsabilidade do controle social democrático do SUS. 2. ed. Brasília-DF, 2013.

BRASIL. Lei n. 8.080, de 19 de setembro de 1990. Dispõe sobre as condições para a promoção, proteção e recuperação da saúde, a organização e o funcionamento dos serviços correspondentes e dá outras providências. Brasília-DF, 1990a. Disponível em: http://www.planalto.gov.br/ccivil_03/leis/L8080.htm. Acesso em: 20 maio 2019.

BRASIL. Lei n. 8.142, de 28 de dezembro de 1990. Dispõe sobre a participação da comunidade na gestão do Sistema Único de Saúde (SUS) e sobre as transferências intergovernamentais de recursos financeiros na área da saúde e dá outras providências. Brasília-DF, 1990b. Disponível em: http://www.planalto.gov. br/ccivil_03/leis/L8142.htm. Acesso em: 20 maio 2019.

BRASIL. Constituição da República Federativa do Brasil de 1988. Brasília-DF, 1988. Disponível em: http:// www.planalto.gov.br/ccivil_03/constituicao/constituicaocompilado.htm. Acesso em: 20 maio 2019.

BRASIL. Ministério da Saúde. Relatório final da 8a Conferência Nacional de Saúde. Brasília-DF, 1986. Disponível em: http://bvsms.saude.gov.br/bvs/publicacoes/8_conferencia_nacional_saude_relatorio_final. pdf.Acesso em: 20 maio 2019.

CANÇADO, A. C.; VILLELA, L. E.; SAUSEN, J. O. Gestão social e gestão estratégica: reflexões sobre as diferenças e aproximações de conceitos. Revista de Gestão Social e Ambiental - RGSA, São Paulo, v. 10, n. 3, p. 69-84, 2016.

GIL, A. C. Métodos e técnicas de pesquisa social. 7. ed. São Paulo: Atlas, 2019.

KRONEMBERGER, T. S.; MEDEIROS, A. C.; DIAS, A. F. Conselhos municipais: institucionalização e funcionamento. In: TENÓRIO, F. G.; KRONEMBERGER, T. S. (Org.). Gestão social e conselhos gestores. Rio de Janeiro: FGV, 2016. p. 151-82.

LEITE, R. A. F; BRITO, E. S.; SILVA, L. M. C; PALHA, P. F.; VENTURA, C. A. A. Acesso à informação em saúde e cuidado integral: percepção de usuários de um serviço público. Interface, Botucatu, v. 18, n. 51, p. 661-71, 2014.

PAIM, J. S. O que é o SUS. Rio de Janeiro: Fiocruz, 2009.

PAIVA, C. H. A.; TEIXEIRA, L. A. Reforma sanitária e a criação do Sistema Único de Saúde: notas sobre contextos e autores. História, Ciências, Saúde - Manguinhos, Ribeirão Preto, v. 201, n. 12, p. 15-35, 2014. 
PAULA, A. P. P.; KEINERT, T. M. M. Inovações institucionais participativas: uma abordagem exploratória da produção brasileira em Administração Pública na RAP e no EnAPG (1990-2014). Cadernos EBAPE.BR, Rio de Janeiro, v. 14, n. 3, p. 744-58, 2016.

RICCI, R. Controle social: um conceito e muitas confusões. Revista Espaço Acadêmico, Maringá, v. 9, n. 98, p. 9-12, 2009.

SANCHO, L. G.; GEREMIA; D. S.; DAIN, S.; GEREMIA, F.; LEÃO, C. J. S. O processo de regionalização da saúde sob a ótica da teoria dos custos de transação. Ciência \& Saúde Coletiva, Rio de Janeiro, v. 22, n. 4, p. 1121-30, 2017.

SILVA, F. S.; LOPEZ, F. G.; PIRES, R. R. C. Accountability e controle social na administração pública federal. In: SILVA, F. S.; LOPEZ, F. G.; PIRES, R. R. C. (Org.). Estado, instituições e democracia: democracia. Brasília: Ipea, 2010. p. 185-210. v. 2.

TENÓRIO, F. G. Gestão social: território e participação. In: TENÓRIO, F. G. (Org.). Cidadania, território e atores sociais. Rio de Janeiro: FGV, 2016a. p. 61-85.

TENÓRIO, F. G. Uma alternativa: gestão social. Ijuí: Unijuí, 2016 b.

TENÓRIO, F. G. Gestão social: conceito. In: TENÓRIO, F. G.; KRONEMBERGER, T. S. (Org.). Gestão social e conselhos gestores. Rio de Janeiro: FGV, 2016c. p. 13-34.

TENÓRIO, F. G. Um espectro ronda o terceiro setor: o espectro do mercado. Ijuí: Unijuí, 2008.

YIN, R. K. Estudo de caso: planejamento e métodos. 2. ed. Porto Alegre: Bookman, 2001.

ZANI, F. B. A trajetória do sistema de proteção social e o papel dos tecnoburocratas. In: TENÓRIO, F. G.; KRONEMBERGER, T. S. (Org.). Gestão social e conselhos gestores. Rio de Janeiro: FGV, 2016. p. 35-64.

\section{Sobre os autores:}

Juliana da Fonseca Capssa Lima Sausen: Doutoranda e mestra em Desenvolvimento Regional; Especialista em Marketing e graduada em Comunicação Social - Publicidade e Propaganda pela Universidade Regional do Noroeste do Estado do Rio Grande do Sul (UNIJUÍ). Bolsista do Programa de Suporte à Pós-Graduação de Instituições Comunitárias de Educação Superior, pela Coordenação de Aperfeiçoamento de Pessoal de Nível Superior (PROSUC/CAPES). E-mail: jucapssa@gmail.com, Orcid: http://orcid.org/0000-0003-4146-8294

Vanilson Viana Cardoso: Doutorando e mestre em Desenvolvimento Regional; Graduado em Administração e Gestão Pública pela Universidade Regional do Noroeste do Estado do Rio Grande do Sul (UNIJUÍ). Bolsista do Programa de Suporte à Pós-Graduação de Instituições Comunitárias de Educação Superior, pela Coordenação de Aperfeiçoamento de Pessoal de Nível Superior (PROSUC/ CAPES). E-mail: vanilson-cardoso@hotmail.com, Orcid: http://orcid.org/0000-0003-2006-9227

Daniel Knebel Baggio: Doutor em Contabilidade e Finanças pela Universidad de Zaragoza. Especialista em Gestão Financeira pela Universidade Regional do Noroeste do Estado do Rio Grande do Sul (UNIJUÍ). Graduado em Marketing e em Administração pela UNIJUÍ. Formação Pedagógica para o Ensino Técnico e Profissional pelo Sistema de Ensino Gaúcho (SEG). Professor doutor do programa de pós-graduação stricto sensu em Desenvolvimento Regional na UNIJUÍ.

E-mail: baggiod@unijui.edu.br, Orcid: http://orcid.org/0000-0002-6167-2682 
Airton Adelar Mueller: Doutor em Sociologia pela Freie Universität Berlin. Mestre em Desenvolvimento Regional pela Universidade de Santa Cruz do Sul (UNISC). Graduado em Estudos Sociais/História pela UNISC. Professor doutor do programa de pós-graduação stricto sensu em Desenvolvimento Regional na Universidade Regional do Noroeste do Estado do Rio Grande do Sul (UNIJUÍ). E-mail: airton.mueller@unijui.edu.br, Orcid: http://orcid.org/0000-0001-6270-5856 
